\title{
Toric Intraocular Lens Implantation for Correction of Astigmatism in Cataract Patients with Corneal Ectasia
}

\author{
Efstratios A. Parikakis ${ }^{a} \quad$ Irini P. Chatzirallia ${ }^{a}$ asileios G. Peponis ${ }^{a}$ \\ Georgios David $^{\mathrm{b}}$ Spyridon Chalkiadakis ${ }^{\mathrm{a}}$ Panagiotis G. Mitropoulos ${ }^{\mathrm{a}}$

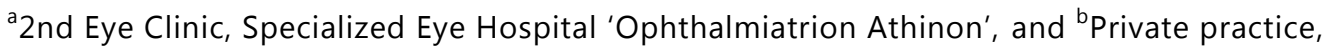 \\ Athens, Greece
}

\section{Key Words}

Phacoemulsification · Keratoconus · Pellucid marginal degeneration · Toric intraocular lens . Intraocular lens · Astigmatism

\begin{abstract}
Our purpose was to examine the long-term efficacy of toric intraocular lens (IOL) implantation in cataract patients with high astigmatism due to corneal ectasia, who underwent phacoemulsification cataract surgery. Five eyes of 3 cataract patients with topographically stable keratoconus or pellucid macular degeneration (PMD), in which phacoemulsification with toric IOL implantation was used to correct high astigmatism, are reported. Objective and subjective refraction, visual acuity measurement and corneal topography were performed in all cases before and after cataract surgery. In all cases, there was a significant improvement in visual acuity, as well as refraction, which remained stable over time. Specifically, in subjective refraction, all patients achieved visual acuity from $7 / 10$ to $9 / 10$ with up to -2.50 cyl. Corneal topography also remained stable. Postoperative follow-up was 18-28 months. Cataract surgery with toric IOL implantation seems to be safe and effective in correcting astigmatism and improving visual function in cataract patients with topographically stable keratoconus or PMD.


Parikakis et al.: Toric Intraocular Lens Implantation for Correction of Astigmatism in Cataract Patients with Corneal Ectasia

\section{Introduction}

Cataract surgery is one of the most common and safe surgical procedures worldwide [1]. Phacoemulsification and recent advances in cataract surgery techniques led to improved postoperative outcomes [1]. Nowadays, along with the improvement in biometry and corneal topography in preoperative examination, patients presenting with cataract can be diagnosed with corneal ectasias, i.e. keratoconus (KC) or pellucid macular degeneration (PMD), a diagnosis that was difficult to be confirmed before [2].

$\mathrm{KC}$ is a relatively common, noninflammatory, progressive disorder of unknown etiology, characterized by steepening of the cornea and corneal ectasia, concluding in cone-shaped protrusion of the cornea [3]. It is considered to involve each layer of the cornea and often leads to high myopia and high astigmatism [3]. KC patients usually present in their teenage years or twenties, complaining of progressive visual blur and distortion secondary to myopia and high astigmatism. Photophobia, glare and monocular diplopia can also be presenting symptoms [3]. PMD is an idiopathic, noninflammatory corneal thinning disorder, characterized by an inferior band of corneal thinning with ectasia of the cornea in and around the thinned area and is associated with significant irregular myopic astigmatism [4]. It typically presents with reduced uncorrected and corrected distance visual acuity [4]. Nevertheless, mild cases of KC or PMD may remain undiagnosed until patients are examined for the presence of cataract.

PMD and KC treatment may differ according to the stage of the disease [5], but spectacles or rigid gas-permeable contact lenses are tried initially in KC or PMD eyes, especially in the early to moderate stages [5]. Additionally, several treatment modalities have been used for patients with $\mathrm{KC}$ or PMD, including lamellar keratoplasty, penetrating keratoplasty, intrastromal corneal ring segments, corneal collagen cross-linking or phakic intraocular lens (IOL) implantation, depending on patients' age [3, 5-9]. Some authors have also used excimer laser in patients with $\mathrm{KC}$, but the safety of this procedure remains controversial [10]. Interestingly enough, toric IOLs have been considered to provide an opportunity to achieve the best distance visual acuity and spectacle independence in cataract patients with high corneal astigmatism, but few reports have been published about toric IOLs in cataract patients with KC or PMD [11-17].

In light of this, our purpose was to examine the efficacy of toric IOL implantation in cataract patients with high astigmatism due to KC or PMD. Three cataract patients with KC and PMD (5 eyes) are presented, in which phacoemulsification with toric IOL implantation was used to correct high astigmatism, comparing refraction (objective and subjective), visual acuity and corneal topography before and after cataract surgery in a long-term follow-up of 18-28 months.

\section{Case Series}

Case 1

A 57-year-old woman presented to our ophthalmology outpatient clinic with a gradually decreased visual acuity in both eyes because of posterior subcapsular cataract. On presentation, best spectacle-corrected visual acuity (BCVA) was 2/10 in the right eye and 4/10 in the left eye, with $-3.75-3.50 \times 165^{\circ}$ and $-1.00-3.50 \times 6^{\circ}$ subjective refraction in the right and left eye, respectively. Automated refractometry showed $-4.75-4.25 \times 164^{\circ}$ with $\mathrm{K} 144.00$ at $180^{\circ}$ and $\mathrm{K} 246.5$ at $90^{\circ}$ in the right eye and $-10.75-5.00 \times 5^{\circ}$ with $\mathrm{K} 146.00$ at $179^{\circ}$ and $\mathrm{K} 2$ 49.75 at $89^{\circ}$ in the left eye. Corneal topography was performed using Orbscan (Bausch and 
Parikakis et al.: Toric Intraocular Lens Implantation for Correction of Astigmatism in Cataract Patients with Corneal Ectasia

Lomb Inc., Rochester, N.Y., USA) and revealed a central corneal thickness of $533 \mathrm{~mm}$ and an inferior temporal displacement of the thinnest point $(512 \mathrm{~mm})$, indicative of $\mathrm{KC}$ in both eyes (fig. 1a, b). Keratometry (K) values for the steep and flat axis were $47.25 \mathrm{D}$ at $86^{\circ}$ and 44.00 $\mathrm{D}$ at $176^{\circ}$, respectively, in the right eye, and $49.8 \mathrm{D}$ at $84^{\circ}$ and $45.6 \mathrm{D}$ at $174^{\circ}$, respectively, in the left eye. It is important to mention that $\mathrm{KC}$ was stable in this patient for the last 2 years, which had been confirmed by previous corneal topographies. Biometry was performed with the IOL Master (Carl Zeiss Meditec, Jena, Germany) to calculate the IOL power for emmetropia using the Sanders-Retzlaff-Kraff theoretical (SRK/T) formula. A web-based toric IOL calculator program was used to determine the optimal cylinder power and alignment axis of the IOL (available at http://www.acrysoftoriccalculator.com) (fig. 1c). A standard phacoemulsification with toric IOL implantation (AcrySof SN60T7 Alcon, Ltd., Fort Worth, Tex., USA), with a spherical power of 19.5 D and a cylinder power of 4.50 D at the IOL plane aligned at $84^{\circ}$, was performed in the right eye. In the left eye, a toric IOL (AcrySof SN60T8) with a spherical power of $16.0 \mathrm{D}$ and a cylinder power of $5.25 \mathrm{D}$ at the IOL plane, being aligned at $89^{\circ}$, was used. Postoperatively, the BCVA was $9 / 10$ with -0.50 sph in the right eye and 8/10 with $-1.50 \mathrm{sph}$ in the left eye, which remained stable at the 18-month and 24month follow-up for the right and left eye, respectively. Corneal topography remained almost stable, with $\mathrm{K}$ values for the steep and flat axis of $47.5 \mathrm{D}$ at $90^{\circ}$ and $43.7 \mathrm{D}$ at $180^{\circ}$, respectively, in the right eye, and $50.0 \mathrm{D}$ at $94^{\circ}$ and $46.0 \mathrm{D}$ at $4^{\circ}$, respectively, in the left eye. The toric IOL alignment axis, as determined by slit-lamp biomicroscopy, remained at the same degrees at the end of the follow-up for both eyes (fig. 1d).

\section{Case 2}

A 72-year-old woman presented to our outpatient clinic with decreased visual acuity in both eyes. Slit-lamp examination showed bilateral nuclear cataract. The BCVA was 4/10 in both eyes with $+1.00-4.25 \times 90^{\circ}$ and $+1.00-5.00 \times 91^{\circ}$ in the right and left eye, respectively. Automated refractometry showed $+1.50-5.25 \times 106^{\circ}$ with $\mathrm{K} 140.25$ at $92^{\circ}$ and $\mathrm{K} 254.75$ at $2^{\circ}$ in the right eye and $-8.0 \times 98^{\circ}$ with $\mathrm{K} 141.75$ at $106^{\circ}$ and $\mathrm{K} 249.50$ at $16^{\circ}$ in the left eye. Orbscan confirmed PMD in both eyes (fig. $2 \mathrm{a}, \mathrm{b}$ ), which had been known and stable for the last 3 years. $\mathrm{K}$ values for the steep and flat axis were $39.28 \mathrm{D}$ at $93^{\circ}$ and $54.7 \mathrm{D}$ at $3^{\circ}$, respectively, in the right eye, and $39.7 \mathrm{D}$ at $106^{\circ}$ and $48.3 \mathrm{D}$ at $16^{\circ}$, respectively, in the left eye. Lens power calculation was performed as described for case 1 . A standard phacoemulsification with toric IOL was performed in both eyes. In the right eye, a toric IOL (AcrySof SN60T9) with a spherical power of 9.5 D and a cylinder power of $6.00 \mathrm{D}$ at the IOL plane was implanted at an axis of $3^{\circ}$. In the left eye, a toric IOL (AcrySof SN60T9) with a spherical power of $16.5 \mathrm{D}$ and a cylinder power of $6.0 \mathrm{D}$ at the IOL plane was implanted at $14^{\circ}$. Postoperatively, the BCVA was $7 / 10$ with $-2.50 \times 80^{\circ}$ in the right eye and $8 / 10$ with $-1.50 \times$ $100^{\circ}$ in the left eye, which remained stable at the 24- and 28-month follow-up for the right and left eye, respectively. Corneal topography remained almost stable, with $\mathrm{K}$ values for the steep and flat axis of $53.3 \mathrm{D}$ at $180^{\circ}$ and $38.5 \mathrm{D}$ at $90^{\circ}$, respectively, in the right eye, and $48.6 \mathrm{D}$ at $15^{\circ}$ and $39.9 \mathrm{D}$ at $105^{\circ}$, respectively, in the left eye. The toric IOL alignment axis, as determined by slit-lamp biomicroscopy, was at $5^{\circ}$ in the right eye and at $15^{\circ}$ in the left eye (fig. 1d). The patient was satisfied with the postoperative visual outcomes at the end of the follow-up.

Case 3

A 72-year-old man presented to our outpatient clinic with decreased visual acuity in the right eye due to cataract. The BCVA was $3 / 10$ with $-2.00-2.00 \times 60^{\circ}$. Automated refractometry showed $-8.00-3.25 \times 58^{\circ}$ with $\mathrm{K} 142.25$ at $62^{\circ}$ and $\mathrm{K} 245.5$ at $152^{\circ}$ in the right eye. 
Parikakis et al.: Toric Intraocular Lens Implantation for Correction of Astigmatism in Cataract Patients with Corneal Ectasia

Orbscan showed changes consistent with PMD (fig. 3a, b), which had been stable for the last 2 years. $\mathrm{K}$ values for the steep and flat axis were $47.3 \mathrm{D}$ at $155^{\circ}$ and $42.9 \mathrm{D}$ at $65^{\circ}$, respectively. Lens power calculation was performed as described for case 1. A standard phacoemulsification was performed and a toric IOL (AcrySof SN60T5) with a spherical power of $15.5 \mathrm{D}$ and a cylinder power of $3.00 \mathrm{D}$ at the IOL plane was implanted. Postoperatively, the BCVA was $9 / 10$ with $-0.50-0.50 \times 73^{\circ}$ in the right eye which remained stable in the 1-year followup. Corneal topography remained almost stable, with $\mathrm{K}$ values for the steep and flat axis of $47.1 \mathrm{D}$ at $155^{\circ}$ and $42.8 \mathrm{D}$ at $65^{\circ}$, respectively. The patient was satisfied with the postoperative visual outcomes at the 18-month follow-up.

Altogether, in all cases, there was a significant improvement in BCVA, as well as in refraction, which remained stable over time, as illustrated in table 1. Specifically, in subjective refraction, all patients achieved BCVA from $7 / 10$ to $9 / 10$ with up to -2.50 cyl. Corneal topography also remained stable. No IOL misalignment or other complications occurred and all patients were satisfied by the postoperative outcome.

Written informed consent was obtained from all patients.

\section{Discussion}

In this case series, we present 3 cases with cataract and high astigmatism due to nonprogressive KC ( 2 eyes) or PMD ( 3 eyes), who underwent cataract extraction and toric IOL implantation. The principal message is that all patients showed a marked improvement in BCVA and subjective refraction, while corneal topography findings remained stable during the follow-up period of 18-28 months. Therefore, phacoemulsification with toric IOL implantation seems to be an effective method in correcting high astigmatism in cataract patients with stable KC or PMD.

Although there are several new effective techniques to correct astigmatism due to $\mathrm{KC}$ or PMD, the correction of high astigmatism in cataract patients presenting with KC or PMD continues to be challenging. Reduced visual acuity due to KC or PMD is initially managed with spectacles or contact lenses, either toric or rigid gas-permeable lenses, to mask the irregular astigmatism [3]. Intracorneal ring segments (ICRS) have recently been approved for reduction of myopia and irregular astigmatism due to $\mathrm{KC}$, improving objective visual outcomes and restoring functional vision [3, 7]. Nevertheless, ICRS have been reported to present complications, such as epithelial defects, anterior and posterior perforations during channel creation, extension of incision toward the visual axis, shallow placement of implants, infectious keratitis, stromal thinning, epithelial breakdown, corneal melting or intrastromal deposits, and are not used as a primary treatment in cataract patients [3, 7]. Furthermore, after ICRS implantation, high refractive errors may remain and most patients require spectacles or contact lenses again [7].

On the other hand, phakic IOLs or Artisan phakic IOLs were used for the correction of astigmatism in young patients with $\mathrm{KC}$, providing encouraging results, although they could only be used in cases with stable $\mathrm{KC}[3,6]$. An option in patients with $\mathrm{KC}$ and a clear natural lens is refractive lens exchange with a toric IOL implantation in the capsular bag [17]. In addition, corneal collagen cross-linking was used effectively to stabilize the biomechanically weakened collagen in $\mathrm{KC}$; however, this technique can only be used in young patients and its effect is not distributed homogenously over the corneal depth [9].

Interestingly, few cataract patients with KC or PMD and toric IOL implantation for the correction of astigmatism have been reported [4, 5, 13-16]. Toric IOLs are used ideally in patients with regular astigmatism. Cataract surgery with a toric IOL implantation can be a 
Parikakis et al.: Toric Intraocular Lens Implantation for Correction of Astigmatism in Cataract Patients with Corneal Ectasia

suitable option to correct high levels of astigmatism and myopia in patients with $\mathrm{KC}$ if the risk of progression is minimal $[4,18,19]$. Before implanting the toric IOL, the patients' individual risk of progression should be analyzed. A careful history taking is needed to explore the level of BCVA the patient had before cataract formation occurred and to determine whether signs of KC progression are present $[18,19]$. Risk factors that have been associated with progression of KC include young age, a positive family history of KC, steep keratometric values at baseline, changes in refractive error and possibly eye rubbing [19]. In practice, clinical findings and corneal topography abnormalities, such as a high central $\mathrm{K}$ value and an increased amount of steepening of the inferior cornea compared with the superior cornea, may be used to assess the risk of progression [19]. Because of the age of the 3 patients presented in our case series, we regarded the risk of progression to be minimal.

AcrySof toric IOL is considered to be one of the most commonly used toric IOL in cataract surgery [20]. It has been found to be effective in the reduction of refractive astigmatism, providing good visual outcomes [5]. The AcrySof toric IOL is available in cylinder powers up to $6.0 \mathrm{D}$ (SN60T9) at the IOL plane, corresponding to $4.11 \mathrm{D}$ at the corneal plane [5]. It is hydrophobic acrylic with open-loop modified L-haptics and $6.0 \mathrm{~mm}$ optic diameter. The axis marks on the IOL indicate the flat meridian of the toric component on the posterior surface of the IOL [5].

Another challenge in cataract patients with KC or PMD with high astigmatism and myopia is IOL power calculation. Accurate axial length, $\mathrm{K}$ values and astigmatism axis measurements must be obtained [20]. Corneal topography is a valuable diagnostic tool for diagnosing subclinical KC, providing data for $\mathrm{KC}$ screening and progression of the disease, including anterior and posterior evaluation and best-fit sphere, corneal pachymetry, as well as $\mathrm{K}$ values [3]. Because of the irregular astigmatism in our patients, we used the $\mathrm{K}$ values and axis obtained with the Orbscan and then compared them with those derived from the IOL Master, finding no significant differences. The spherical power of the IOL was calculated using the SRK/T formula. Thebpatiphat et al. [18] compared the SRK II and SRK/T IOL formulas in patients with $\mathrm{KC}$ and suggested that the SRK II formula might provide the most accurate IOL power in patients with mild KC. However, in moderate and severe KC, IOL calculations were less accurate and no differences in calculation formulas could be found [18]. As far as the axis is concerned, we have not seen any IOL rotation, in line with other studies suggesting that IOL rotation is $<4^{\circ}$ [21].

A potential limitation pertains to the fact that the number of cases reported here is not adequate enough to prove the efficacy of this method for the correction of astigmatism in cataract patients with KC or PMD. Moreover, one should take into account that the improvement in BCVA derives not only from the correction of refractive astigmatism due to $\mathrm{KC}$, but also from the removal of cataract.

In conclusion, our case series suggests that phacoemulsification with toric IOL implantation in cataract patients with stable KC or PMD seems to be effective in correcting high astigmatism and achieving optimal visual outcomes. Additionally, Orbscan is considered an accurate tool for obtaining $\mathrm{K}$ values, showing no significant differences compared to IOL Master. Further studies with a larger sample size should be performed to confirm the longterm efficacy and stability of toric IOL implantation in patients with cataract and a presumably stable KC or PMD.

\section{Disclosure Statement}

The authors have no conflicts of interest. 
Parikakis et al.: Toric Intraocular Lens Implantation for Correction of Astigmatism in Cataract Patients with Corneal Ectasia

\section{References}

1 Syam PP, Eleftheriadis H, Casswell AG, Brittain GP, McLeod BK, Liu CS: Clinical outcome following cataract surgery in very elderly patients. Eye 2004;18:59-62.

2 De Cunha DA, Woodward EG: Measurement of corneal topography in keratoconus. Ophthalmic Physiol Opt 1993;13:377-382.

-3 Rabinowitz YS: Keratoconus. Surv Ophthalmol 1998;42:297-319.

4 Luck J: Customized ultra-high-power toric intraocular lens implantation for pellucid marginal degeneration and cataract. J Cataract Refract Surg 2010;36:1235-1238.

-5 Visser N, Ruíz-Mesa R, Pastor F, Bauer NJ, Nuijts RM, Montés-Micó R: Cataract surgery with toric intraocular lens implantation in patients with high corneal astigmatism. J Cataract Refract Surg 2011;37:1403-1410.

6 Venter J: Artisan phakic intraocular lens in patients with keratoconus. J Refract Surg 2009;25:759-764.

-7 Coskunseven E, Onder M, Kymionis GD, Diakonis VF, Arslan E, Tsiklis N, Bouzoukis DI, Pallikaris I: Combined Intacs and posterior chamber toric implantable Collamer lens implantation for keratoconic patients with extreme myopia. Am J Ophthalmol 2007;144:387-389.

8 Kamiya K, Shimizu K, Kobashi H, Komatsu M, Nakamura A, Nakamura T, Ichikawa K: Clinical outcomes of posterior chamber toric phakic intraocular lens implantation for the correction of high myopic astigmatism in eyes with keratoconus: 6-month follow-up. Graefes Arch Clin Exp Ophthalmol 2011;249:1073-1080.

-9 Güell JL, Morral M, Malecaze F, Gris O, Elies D, Manero F: Collagen crosslinking and toric iris-claw phakic intraocular lens for myopic astigmatism in progressive mild to moderate keratoconus. J Cataract Refract Surg 2012;38:475-484.

10 Kasparova EA, Kasparov AA: Six-year experience with excimer laser surgery for primary keratoconus in Russia. J Refract Surg 2003;19:S250-S254.

-11 Bauer NJ, de Vries NE, Webers CA, Hendrikse F, Nuijts RM: Astigmatism management in cataract surgery with the AcrySof toric intraocular lens. J Cataract Refract Surg 2008;34:1483-1488.

12 Holland E, Lane S, Horn JD, Ernest P, Arleo R, Miller KM: The AcrySof toric intraocular lens in subjects with cataract and corneal astigmatism: a randomized, subject-masked, parallel-group, 1-year study. Ophthalmology 2010;117:2104-2111.

-13 Sauder G, Jonas JB: Treatment of keratoconus by toric foldable intraocular lenses. Eur J Ophthalmol 2003;13:577-579.

14 Navas A, Suárez R: One-year follow-up of toric intraocular lens implantation in forme fruste keratoconus. J Cataract Refract Surg 2009;35:2024-2027.

15 Visser N, Gast ST, Bauer NJ, Nuijts RM: Cataract surgery with toric intraocular lens implantation in keratoconus: a case report. Cornea 2011;30:720-723.

16 Ramirez-Miranda A, Jaimes M, Graue-Hernandez EO, Ramirez-Luquin T, Navas A: Toric intraocular lens in keratoconus. Cornea 2012;31:335-336.

-17 Jaimes M, Xacur-García F, Alvarez-Melloni D, Graue-Hernández EO, Ramirez-Luquín T, Navas A: Refractive lens exchange with toric intraocular lenses in keratoconus. J Refract Surg 2011;27:658-664.

18 Thebpatiphat N, Hammersmith KM, Rapuano CJ, Ayres BD, Cohen EJ: Cataract surgery in keratoconus. Eye Contact Lens 2007;33:244-246.

19 Li X, Yang H, Rabinowitz YS: Longitudinal study of keratoconus progression. Exp Eye Res 2007;85:502-507.

20 Kersey JP, O’Donnell A, Illingworth CD: Cataract surgery with toric intraocular lenses can optimize uncorrected postoperative visual acuity in patients with marked corneal astigmatism. Cornea 2007;26:133135.

21 Zuberbuhler B, Signer T, Gale R, Haefliger E: Rotational stability of the AcrySof SA60TT toric intraocular lenses: a cohort study. BMC Ophthalmol 2008;8:8. 
Parikakis et al.: Toric Intraocular Lens Implantation for Correction of Astigmatism in Cataract Patients with Corneal Ectasia

Table 1. Data of 5 eyes (3 cases) with cataract and corneal ectasia

\begin{tabular}{|c|c|c|c|c|c|c|}
\hline & & \multicolumn{2}{|l|}{ Case 1} & \multicolumn{2}{|l|}{ Case 2} & \multirow{2}{*}{$\frac{\text { Case } 3}{\text { right eye }}$} \\
\hline & & right eye & left eye & right eye & left eye & \\
\hline \multirow[t]{2}{*}{ VA } & pre & $2 / 10$ & $4 / 10$ & $4 / 10$ & $4 / 10$ & $3 / 10$ \\
\hline & post & $9 / 10$ & $8 / 10$ & $7 / 10$ & $8 / 10$ & $9 / 10$ \\
\hline \multirow[t]{2}{*}{ IOL Master } & K1 & $43.77 \mathrm{D}$ at $4^{\circ}$ & $46.23 \mathrm{D}$ at $2^{\circ}$ & $39.20 \mathrm{D}$ at $90^{\circ}$ & $39.20 \mathrm{D}$ at $105^{\circ}$ & $\mathrm{N} / \mathrm{A}$ \\
\hline & K2 & $47.34 \mathrm{D}$ at $94^{\circ}$ & $50.37 \mathrm{D}$ at $92^{\circ}$ & $54.7 \mathrm{D}$ at $0^{\circ}$ & $48.28 \mathrm{D}$ at $15^{\circ}$ & $\mathrm{N} / \mathrm{A}$ \\
\hline \multirow[t]{2}{*}{ Orbscan K1 } & pre & $44.0 \mathrm{D}$ at $176^{\circ}$ & $45.6 \mathrm{D}$ at $174^{\circ}$ & $39.2 \mathrm{D}$ at $93^{\circ}$ & $39.7 \mathrm{D}$ at $106^{\circ}$ & $42.9 \mathrm{D}$ at $65^{\circ}$ \\
\hline & post & $43.7 \mathrm{D}$ at $180^{\circ}$ & $46.0 \mathrm{D}$ at $4^{\circ}$ & $38.5 \mathrm{D}$ at $90^{\circ}$ & $39.9 \mathrm{D}$ at $105^{\circ}$ & $42.8 \mathrm{D}$ at $65^{\circ}$ \\
\hline \multirow[t]{2}{*}{ Orbscan K2 } & pre & $47.25 \mathrm{D}$ at $86^{\circ}$ & $49.8 \mathrm{D}$ at $84^{\circ}$ & $54.7 \mathrm{D}$ at $3^{\circ}$ & $48.3 \mathrm{D}$ at $16^{\circ}$ & $47.3 \mathrm{D}$ at $155^{\circ}$ \\
\hline & post & $47.5 \mathrm{D}$ at $90^{\circ}$ & $50.0 \mathrm{D}$ at $94^{\circ}$ & $53.3 \mathrm{D}$ at $180^{\circ}$ & $48.6 \mathrm{D}$ at $15^{\circ}$ & $47.1 \mathrm{D}$ at $155^{\circ}$ \\
\hline \multirow[t]{2}{*}{ Ref K1 } & pre & 44.0 at $180^{\circ}$ & 46.0 at $179^{\circ}$ & 40.25 at $92^{\circ}$ & 41.75 at $106^{\circ}$ & 42.25 at $62^{\circ}$ \\
\hline & post & 44.00 at $177^{\circ}$ & 46.25 at $174^{\circ}$ & 39.75 at $94^{\circ}$ & 42.50 at $98^{\circ}$ & 41.75 at $64^{\circ}$ \\
\hline \multirow[t]{2}{*}{ Ref K2 } & pre & 46.5 at $90^{\circ}$ & 49.75 at $89^{\circ}$ & 54.75 at $2^{\circ}$ & 49.5 at $16^{\circ}$ & 45.5 at $152^{\circ}$ \\
\hline & post & 46.25 at $87^{\circ}$ & 50.25 at $84^{\circ}$ & 54.25 at $4^{\circ}$ & 50.00 at $8^{\circ}$ & 45.00 at $154^{\circ}$ \\
\hline \multirow[t]{2}{*}{ Refraction } & pre & $-4.75-4.25 \times 164^{\circ}$ & $-10.75-5.00 \times 5^{\circ}$ & $+1.50-5.25 \times 106^{\circ}$ & $-8.00 \times 98^{\circ}$ & $-8.00-3.25 \times 58^{\circ}$ \\
\hline & post & $-0.75+0.25 \times 120^{\circ}$ & $-1.75-0.50 \times 30^{\circ}$ & $+6.00-13.00 \times 79^{\circ}$ & $+1.00-5.00 \times 103^{\circ}$ & N/A \\
\hline Subjective & pre & $-3.75-3.50 \times 165^{\circ}$ & $-1.00-3.50 \times 6^{\circ}$ & $+1.00-4.25 \times 90^{\circ}$ & $+1.00-5.00 \times 91^{\circ}$ & $-2.00-2.00 \times 60^{\circ}$ \\
\hline refraction & post & $-0.50 \mathrm{sph}$ & $-1.50 \mathrm{sph}$ & $-2.50 \times 80^{\circ}$ & $-1.50 \times 100^{\circ}$ & $-0.50-0.50 \times 73^{\circ}$ \\
\hline \multicolumn{2}{|c|}{ Follow-up, months } & 18 & 24 & 24 & 28 & 18 \\
\hline
\end{tabular}

$\mathrm{VA}=$ Visual acuity; Ref = values derived from automated refractometry; N/A = not available. 
Parikakis et al.: Toric Intraocular Lens Implantation for Correction of Astigmatism in Cataract Patients with Corneal Ectasia
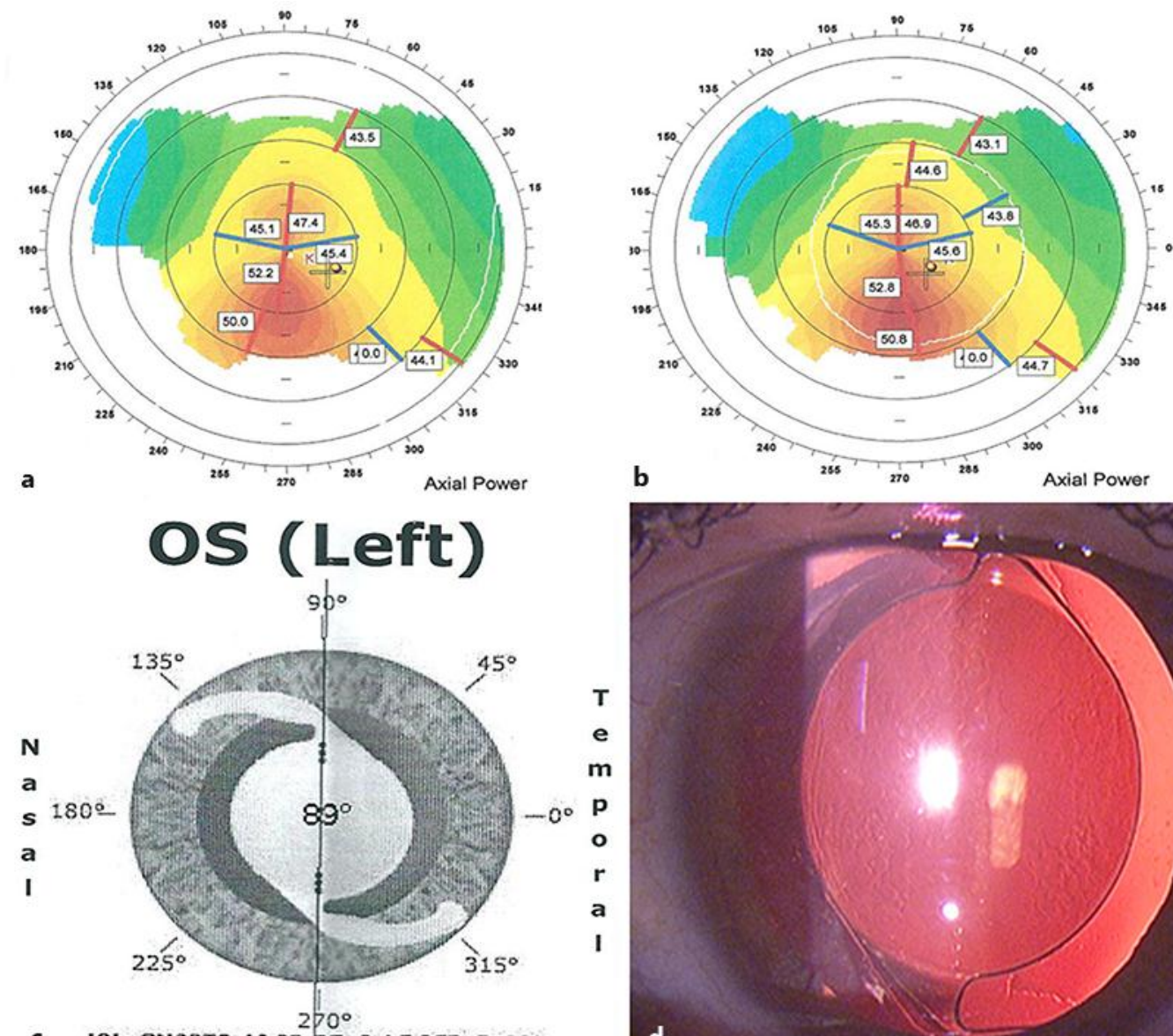

c IOL: SNGOT8 $16.0 \mathrm{D}$ SE, CYI:5.25D@ $8^{\circ}$

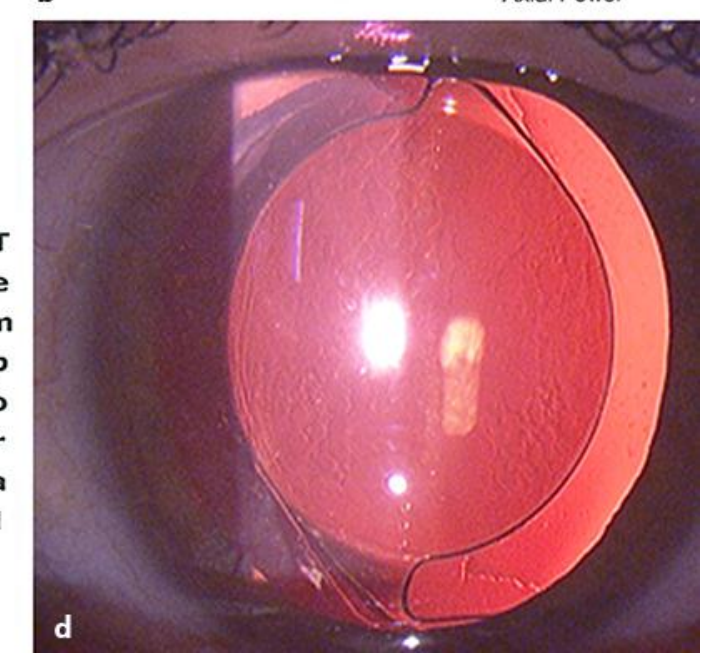

Fig. 1. Case 1, left eye. Orbscan keratometric map before (a) and after surgery (b), showing stability in topographic astigmatism. Toric IOL software calculation with suggested IOL position (c) and final IOL position (d), with IOL marks aligned according to the suggested position. 


\section{Case Reports in \\ Ophthalmology}

\begin{tabular}{l|l}
\hline Case Rep Ophthalmol 2013;4:219-228 \\
\hline DOI: 10.1159/000356532 & $\begin{array}{l}\text { ○ } 2013 \text { S. Karger AG, Basel } \\
\text { www.karger.com/cop }\end{array}$ \\
\hline
\end{tabular}

Parikakis et al.: Toric Intraocular Lens Implantation for Correction of Astigmatism in Cataract Patients with Corneal Ectasia
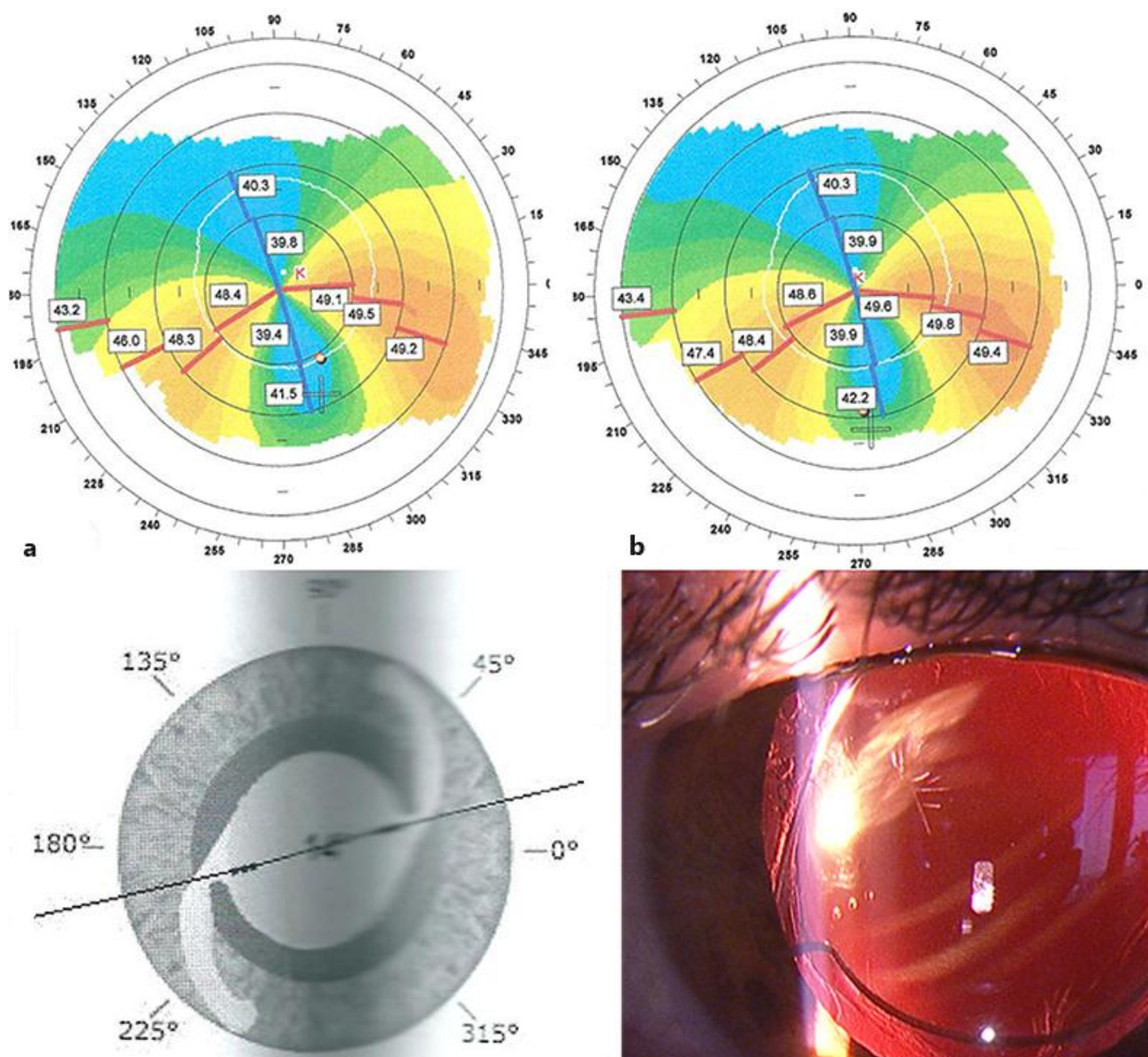

\section{c IOL: SN60T9 16.50}

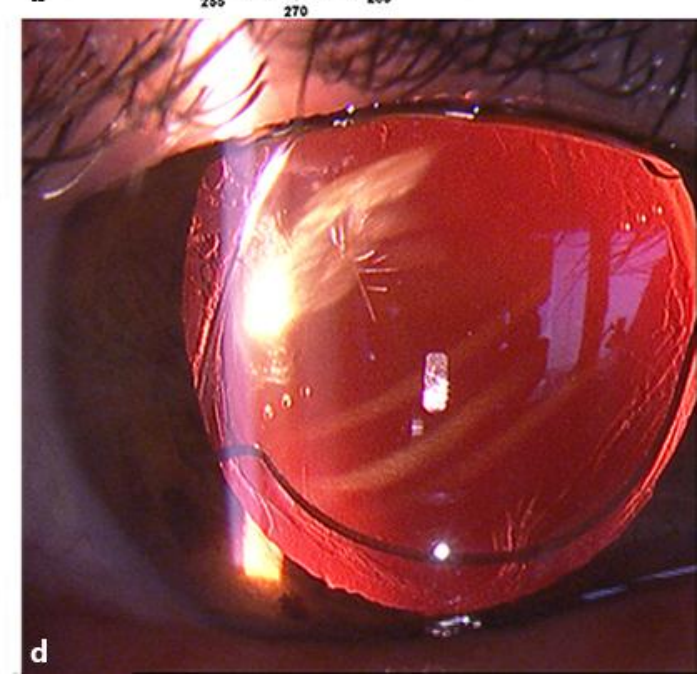

Fig. 2. Case 2, left eye. Orbscan keratometric map before (a) and after surgery (b), showing stability in topographic astigmatism. Toric IOL software calculation with suggested IOL position (c) and final IOL position (d), with IOL marks aligned according to the suggested position. 
Parikakis et al.: Toric Intraocular Lens Implantation for Correction of Astigmatism in Cataract Patients with Corneal Ectasia
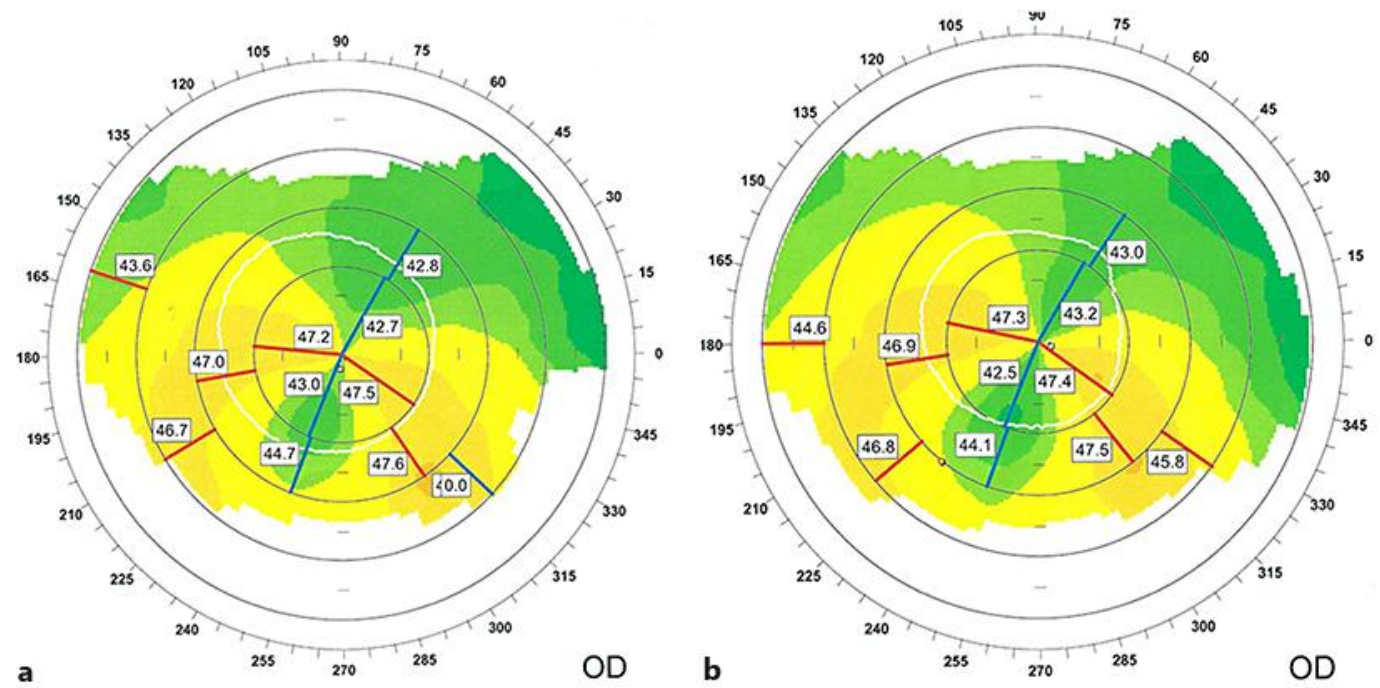

Fig. 3. Case 3, right eye. Orbscan keratometric map before (a) and after surgery (b). 